\title{
Produção e valorização do espaço urbano: o caso dos novos loteamentos de Alfenas-MG ${ }^{1}$
}

\author{
Production and valorization of the urban space: the case of the new subdivisions of Alfenas- \\ MG $^{2}$
}

\author{
Ariádina Aparecida Lelis Ribeiro \\ Graduada Geografia Licenciatura - UNIFAL-MG, B rasil \\ ariadinaaparecidalelisribeiro@gmail.com
}

Flamarion Dutra Alves Prof. Dr. Geografia - Unifal-MG, Brasil flamarion.dutra@unifal-mg.edu.br

\begin{abstract}
Resumo
Este trabalho apresenta um estudo da expansão urbana no município de Alfenas-MG através dos novos loteamentos horizontais e suas implicações sobre a estrutura socioespacial da cidade. Evidencia-se que o crescimento horizontal da cidade está sendo impulsionado por uma intensa especulação imobiliária, viabilizada pelo poder, acumulação e competitividade pelo espaço. Tal processo provoca alterações na paisagem urbana e rural e, afeta os valores das residências já instaladas próximas aos novos loteamentos, assim como também dos moradores e dificulta o acesso às terras das camadas de menor renda, contribuindo assim, para o aprofundamento da desigualdade socioespacial, da exclusão social e segregação dos bairros da cidade. Buscou-se através de pesquisas bibliográficas, trabalhos de campo realizados e consultas em sites IBGE, entre outros, mostrar que esses novos loteamentos se tratam de uma visível especulação e antecipação espacial, pois a cidade, por mais que é considerada como média, não possui porte e demanda para tais empreendimentos, assim como também não possui estruturas para atender novas demandas sociais. Além disso, é plausível de atenção para que não ocorra novos empreendimentos imobiliários e que sejam realizados estudos e um planejamento urbano mais coerente com os ensejos da população.
\end{abstract}

Palavras-chave: Produção do espaço, especulação imobiliária, cidade média, segregação, acumulação.

\begin{abstract}
This research presents a study of urban expansion in the city of Alfenas-MG through the new horizontal subdivisions and their implications in the socio-spatial structure of the city. The horizontal growth of the city is being driven by intense real estate speculation, made feasible by the power, accumulation and competitiveness by the space. This process causes changes in the urban and rural landscape and affects the values of residences already installed in the vicinity of the new subdivisions, as well as of the residents and demanding access to the lands of the lower-income layers, thus contributing to the deepening of the socio-spatial conditions Inequality, Social exclusion and segregation of the city's neighborhoods. It was searched through bibliographical

\footnotetext{
${ }^{1}$ A pesquisa aqui apresentada, são apontamentos do Trabalho de Conclusão de Curso apresentado como parte dos requisitos para obtenção do título de Licenciatura em Geografia pela Universidade Federal de Alfenas-MG, no ano de 2017.

${ }^{2}$ The research presented here are notes of the Course Completion Work presented as part of the requirements for obtaining a degree in Geography by the Federal University of Alfenas-MG, in the year 2017.
} 
researches, field works and consultations in the IBGE, sites, among others, to show that these new subdivisions are a visible speculation and a spatial anticipation, since the city, although considered average, does not have size and demand By these companies, nor do they have the structures to meet new social demands. Besides, it is plausible to ensure that no new real estate developments occur and that studies and urban planning are conducted that are more consistent with the opportunities of the population.

Keywords: Production of space, real estate speculation, middle-sized city, segregation, accumulation.

\section{INTRODUÇÃO}

Segundo Harvey (2005, p. 43), “o sistema capitalista é, portanto, muito dinâmico e inevitavelmente expansível; esse sistema cria uma força permanentemente revolucionária, que, incessante e constantemente, reforma o mundo em que vivemos". Assim podemos relacionar o capitalismo à expansão urbana. Partindo dessa premissa, esse trabalho busca relacionar as questões socioespaciais que envolvem o caso dos novos loteamentos horizontais de Alfenas - MG.

Alfenas está sofrendo uma grande expansão de loteamentos horizontais e não há como discutir a expansão urbana sem tratar do desenvolvimento do capitalismo. O Estado através de iniciativas de programas sociais e de crédito fácil para financiamentos, contribuem diretamente para isso, estimulando a aquisição de novas áreas para construção de empreendimentos imobiliários.

A partir dessa expansão, busca-se nessa pesquisa questionar três problemáticas: qual a real necessidade da quantidade de novos loteamentos horizontais no município de Alfenas-MG? Há uma demanda válida para esses novos lotes? Quais as consequências sociais e econômicas desses novos espaços? Assim, esse trabalho tem como objetivo analisar a organização e produção dos novos loteamentos de Alfenas MG, como também quais impactos os mesmos causarão na sociedade através dessa expansão imobiliária. Além dos novos loteamentos, será tratado a questão dos loteamentos fechados que atendem a um público específico e ao mesmo tempo fazem com que ocorra a segregação espacial.

Nesta direção, o presente trabalho busca discutir a utilização e oferta desses novos espaços, pois Alfenas é considerada uma cidade média e com uma crescente população. Deve-se muito esse crescimento a ampliação das universidades, sobretudo a Universidade Federal de Alfenas, e também sua importância no setor de prestação de serviços, em especial a saúde.

\section{METODOLOGIA}

Para execução desta pesquisa, partiu-se da problemática: Qual a real necessidade da quantidade de novos loteamentos e condomínios em Alfenas? Há uma demanda válida para esses lotes? E quais as consequências sociais e econômicas desses novos espaços? 
Inicialmente, foi realizada uma discussão teórica sobre temas como segregação urbana com base em Sposito (2012), especulação imobiliária e loteamentos horizontais abertos e fechados, além da expansão do espaço urbano em cidades médias consultando Corrêa (2013).

Através de pesquisas diversas, foi desenvolvida uma breve caracterização da ocupação urbana de Alfenas, consultando dados secundários sobre a cidade e TCC do curso de Geografia da UNIFAL-MG, consulta de dados secundários para a caracterização socioeconômica de Alfenas no site do IBGE (Cidades, SIDRA, Stat Card), IMRS (Índice Mineiro de Responsabilidade Social) e outras obras sobre a questão urbana em Alfenas.

Após as consultas dos dados secundários, foram realizadas pesquisas em campo para verificação dos empreendimentos imobiliários e realização de entrevistas para coleta de informações sobre os novos loteamentos. Foram organizadas as informações sobre os loteamentos horizontais abertos e fechados em Alfenas, conforme tabela 1.

Tabela 1 - Descrição dos novos loteamentos horizontais criados em Alfenas entre 2010-2015.

\begin{tabular}{ll}
\hline & Loteamentos/ Condomínios \\
\hline Ano de criação: & Número de lotes: \\
Área total: & Áreas de lazer: \\
Área média dos lotes: & Percentual vendido: \\
Valor do $\mathrm{m}^{2}$ ou médio dos lotes: & Total de moradores: estimativa \\
\hline
\end{tabular}

Fonte: Autora, 2016.

Foi feito um mapa com a localização dos novos empreendimentos imobiliários, mostrando a expansão urbana e os perfis socioeconômicos dos novos loteamentos horizontais. Criou-se uma classificação dos loteamentos com o valor médio de cada lote, sendo agrupados em: Baixo Padrão, valor inferior a $\mathrm{R} \$ 40.000,00$; Médio Padrão: os de $\mathrm{R} \$ 50.000,00$ até $\mathrm{R} \$ 90.000,00$, e Alto Padrão os loteamentos acima de $\mathrm{R} \$ 90.000,00$.

Por fim, realizou-se trabalhos de campo com entrevistas em cada uma das loteadoras ou imobiliárias responsáveis pelos novos empreendimentos, para identificar a característica socioeconômica de cada um dos mesmos.

No dia 20/01/2016 iniciou-se a coleta de dados dos novos loteamentos. Nesse mesmo dia, o $1^{\circ}$ trabalho de campo foi nos loteamentos Alda Caetani, Residencial Mont Serrat, Residencial Euroville, Mont Blanc Residence Alfenas, Residencial Floresta, Cidade Jardim e Residencial Cidade Jardim. O $2^{\circ}$ trabalho de campo foi dia 26/01/2016, nos loteamentos Jardim Alto da Boa Vista, Chácaras Recanto da Harmonia, Vila Porto Seguro, Residencial Cidade Universitária e Residencial Crystal. O $3^{\circ}$ e último dia de trabalho de campo foi 06/09/2016 nos loteamentos Jardim Olímpia, Logfenas e Residencial Imperial. 
Um novo trabalho de campo foi realizado no dia 20/10/2016 afim, de fotografar cada um dos novos loteamentos. Também foi realizada algumas anotações das características de cada loteamento, pois alguns já se encontram em fase de construção de moradias, o que ainda não tinha ocorrido no dia 20/01/2016.

Após fazer o trabalho de campo em todos os novos 15 loteamentos (abertos e fechados) e fechar os dados levantados, um novo loteamento foi lançado, o Condomínio Lago Azul, onde foi feito o levantamento de dados e o registro fotográfico realizado em 10/01/2017.

Vale destacar, que os condomínios e loteamentos analisados na pesquisa estão no perímetro urbano e em áreas de expansão, situados na área rural do município de Alfenas. O intuito de incluir esses loteamentos foi de mostrar o processo de ocupação do espaço por parte dos empreendedores imobiliários, sejam eles na cidade ou no que ainda é campo.

\subsection{Caracterização da área de estudo}

Essa pesquisa abrange a cidade de Alfenas-MG (figura 1) com relação a sua expansão através dos novos loteamentos horizontais que surgiram ao decorrer dos anos 2010 a 2016.

Alfenas localiza-se a uma altitude média de $840 \mathrm{~m}$ acima do nível do mar, ocupando uma área (2015) de 850,446 km² de extensão, possui uma densidade demográfica (2010) de 86,75 hab./km². Situa-se no sul de Minas Gerais e sua população estimada em 2016, segundo o IBGE é de 79.222, em 2010 era de 73.774. Sua economia é voltada para o setor de serviços (comércio e prestação de serviços), e grãos e, principalmente, cafeicultura.

Através da tabela 2 podemos notar que do ano de 2006 até 2014 a economia nos setores da agropecuária, indústria e terciário vem aumentando gradativamente. Em destaque e, principalmente o setor terciário, este que abrange o comércio, saúde e educação, sendo de suma importância para o crescimento da economia da cidade de Alfenas-MG. Os mesmos geram fluxos de pessoas de cidades vizinhas que vem para Alfenas em busca de tratamento de saúde especializado; empregos em escolas estaduais e municipais; empregos e compras em lojas e supermercados, principalmente localizados no centro da cidade.

Com o aumento economicamente desses setores desencadeou para que Alfenas se tornasse uma cidade média e se expandisse em favor da modernidade e desenvolvimento. A educação, em destaque, devido as universidades (particular e federal) provoca um desses crescimentos de fluxos de pessoas e uma maior demanda pelo espaço urbano. 


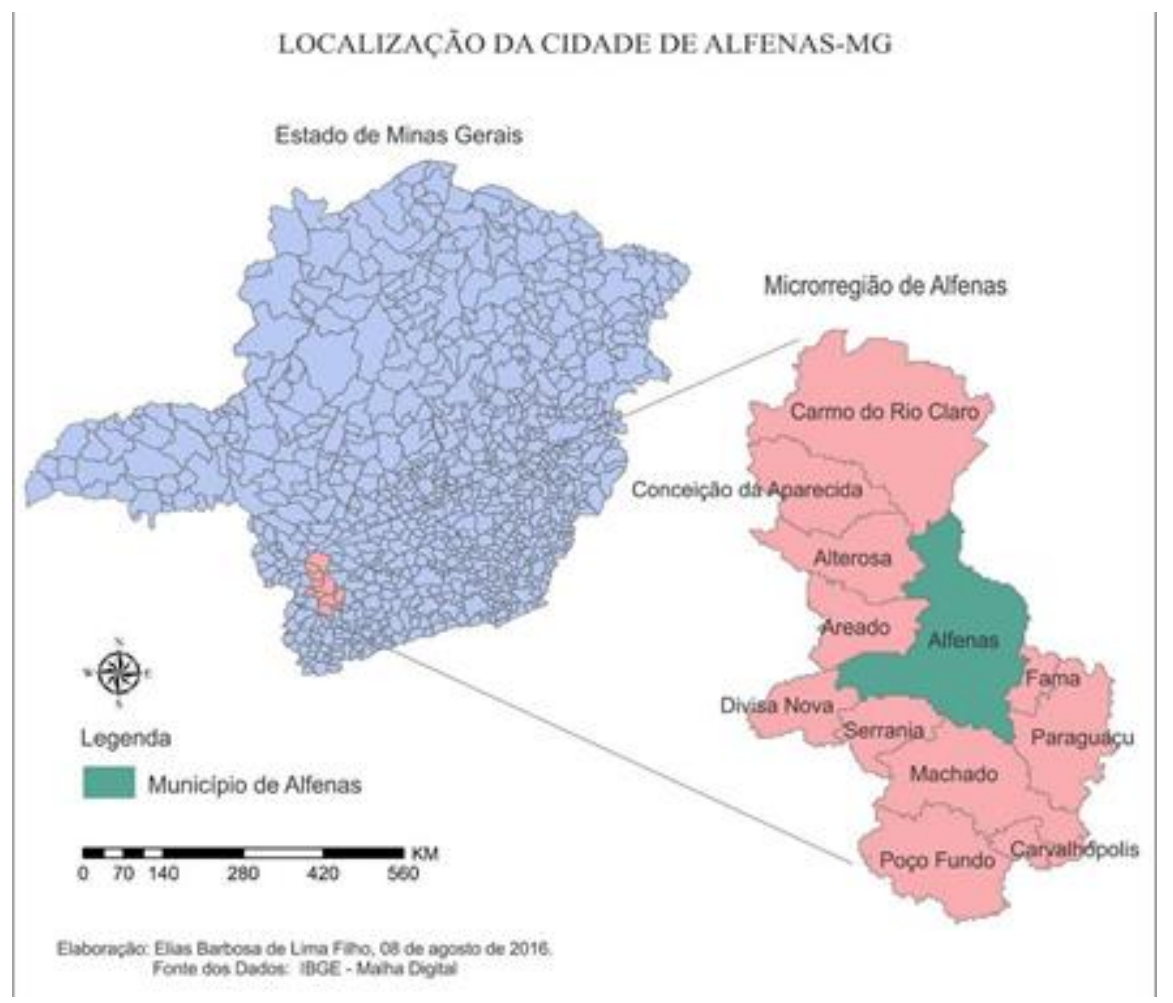

Figura 1 - Mapa de localização da microrregião de Alfenas-MG. Elaborado: Elias Barbosa de Lima Filho, 08 de agosto de 201.

Fonte: IBGE-Malha Digital.

Tabela 2- Desenvolvimento da economia de Alfenas, por segmentos (2006-2014).

\begin{tabular}{cccc}
\hline R\$1.000 & $\mathbf{2 0 0 6}$ & $\mathbf{2 0 1 0}$ & $\mathbf{2 0 1 4}$ \\
\hline PIB & $778.514,00$ & $1.282 .670,00$ & $25.103,11$ \\
Agropecuária & 116.513 & 131.429 & 86.366 \\
Indústria & 153.047 & 198.068 & 273.498 \\
Serviços & 438.569 & 817.831 & 1.124 .534 \\
Administração Pública & 117.300 & 165.492 & 250.722 \\
\hline
\end{tabular}

Fonte: IBGE Cidades, 2016 e IMRS (Índice Mineiro de Responsabilidade Social), 2017.

\section{O CAPITALISMO E A CONSTRUÇÃO DA URBANIZAÇÃO}

Em Alfenas-MG há diversos loteamentos novos por toda a parte da cidade, desde loteamentos que atendem a parte social mais simples, como residenciais populares, até residenciais luxuosos à empresariais que estão na transição do campo e cidade. Essa ligação da cidade ao campo está em constante transformação, como afirma Sposito (2012b, p. 64) “[...] os espaços não são apenas urbanos; existe a cidade e o campo. O modo de produção não produz cidades de um lado e o campo do outro, mas ao contrário, esta produção compreende uma totalidade, com uma articulação intensa entre estes dois espaços”.

Juntamente com esses novos loteamentos, surgem novos nomes de loteadoras e incorporadoras somando-se as já existentes na cidade, podendo se tratar de estratégias e práticas sociais distintas em um único agente. Sposito et al.. (2012a, p. 45) evidencia que: 
[...]uma empresa industrial, pode criar subsidiárias e investir na produção de imóveis ou na criação de loteamentos. A construção de bairros residenciais de expressivo status social e distantes do local onde a empresa industrial está instalada é prática bastante corrente, resultando na produção de espaços diferenciados na cidade".

De acordo com o capital empregado, os movimentos de ocupação e transformação do espaço urbano modificam a paisagem, resultando em diferentes segregações sociais. Segundo Mingione (1977), "a terra urbana passou a interessar ao capital industrial, constituindo, assim como a produção imobiliária, alternativa para a acumulação, deixando de ser meramente um investimento com vistas a amortecer crises cíclicas de acumulação”. (MINGIONE, 1977 apud SPOSITO et al., 2012a, p. 45)

A produção do espaço urbano sofre um processo de transformação acelerada, a respeito disso Harvey (2005, p. 43) diz que "o sistema capitalista é, portanto, muito dinâmico e inevitavelmente expansível; esse sistema cria uma força permanentemente revolucionária, que, incessante e constantemente, reforma o mundo em que vivemos". Desse modo, se dá a produção dos novos loteamentos na cidade de Alfenas, atendendo um mercado capitalista que constantemente está motivado por políticas habitacionais e a liberação de crédito para financiamento. Loteamentos que em muitas vezes tende a atender a um público específico, partindo de residenciais fechados a residenciais abertos, existindo assim, uma segregação espacial.

A formação desses novos loteamentos provoca o surgimento de novas demandas de subcentros de comércio e serviços, afim de atender uma nova população que irá surgir, alterando o perfil atual da cidade. Singer (1987, p. 15) confirma isso, "a cidade proporciona a classe dominante a possibilidade de ampliar territorialmente seu domínio", porém, segundo o mesmo autor, “O “capital” imobiliário é, portanto, um falso capital. Ele é, sem dúvida, um valor que se valoriza, mas a origem de sua valorização não é a atividade produtiva, mas a monopolização do acesso a uma condição indispensável àquela atividade”. (1978, p. 22)

Respondendo a um determinado período do avanço capitalista na produção do espaço, surge através dos imóveis a produção para o mercado, consolidando um capital de circulação.

\footnotetext{
O uso do solo na economia capitalista é regulado pelo mecanismo de mercado, no qual se forma o preço desta mercadoria sui-generis que é o acesso à utilização do espaço. Este acesso pode ser ganho mediante a compra de um direito de propriedade ou mediante o pagamento de um aluguel periódico. (SINGER, 1978, p. 23).
}

As grandes empresas de incorporação são responsáveis por intensificar o marketing na produção imobiliária, principalmente na aplicação de preços e comercialização dos imóveis, a respeito disso, Singer ressalta que: “[...] a demanda por solo urbano muda frequentemente, o preço de determinada área deste espaço que está sujeito a oscilações violentas, o que torna o mercado imobiliário essencialmente especulativo". (SINGER, 1978, p. 23). O que ocorreu a partir de 2010, 
onde vários anúncios de empreendimentos imobiliários surgiram na cidade de Alfenas, e foram veiculados em muitos canais de comunicação como os jornais, sites e propagandas no rádio e na televisão.

Outro fator importante é a localização, pois dependendo de onde o lote se localiza dará maior acessibilidade do indivíduo a determinados pontos da cidade, como área central, mercados, local de trabalho e anel viário. Segundo Nascimento et al.. (2011), os donos de terras situadas no entorno do tecido urbano tendem a se interessar em converter o uso rural de suas áreas para um uso urbano, na expectativa de obter maior remuneração por suas terras. Ou seja, converter terra barata em terra mais cara.

Fica claro, a partir das informações citadas, que a expansão urbana reflete mais do que a demanda social por novas áreas urbanizadas, e sim, um interesse do setor imobiliário por novos empreendimentos, e também o setor público, pois aumentará a malha urbana, consequentemente uma maior arrecadação de impostos.

A indústria de construção imobiliária por meio de estratégias flexíveis, atrai o capital financeiro favorecendo o setor imobiliário através da centralização do capital. De acordo com Aglietta (1986) apud Rufino (2013, p. 144):

[...] a centralização do capital vem, desde a década de 1980, sendo responsável por um processo contínuo de reestruturação produtiva em diversos setores industriais, que passam a ser comandados por grandes corporações /grupos financeiros a partir do imbricamento do capital financeiro e industrial, sendo impostas novas lógicas de reprodução do capital.

Esse avanço capitalista através dos imóveis é para atender a demanda da produção como também da população, atendendo as novas exigências do mercado. Tornando-se uma competividade entre pessoas e empresários por uma boa localização, gerando assim, a especulação imobiliária. Segundo Andrade (1984) apud Pêssoa (2013):

Uma vez implantada uma forma de utilização da terra e, consequentemente, um tipo de espaço, este não se torna definitivo, estático. Com a transformação da economia e da sociedade, outros usos vão sendo dados à terra, ora com o objetivo de modificar a produção, ora para acelerar a atividade produtiva [...] A produção do espaço nunca fica perfeita e acabada, havendo sempre uma reprodução da mesma. (ANDRADE, 1984, p.17)

Assim, também através da especulação imobiliária novos espaços rurais vão sendo consumidos e transformados para atender a demanda capitalista e econômica tanto do Estado quanto do setor imobiliário. 


\title{
3.1. Efeitos da especulação imobiliária
}

Analisando a formação do espaço e as relações da cidade, sabe-se que a todo momento ocorre transformações, dando lugar a uma paisagem representada pelo trabalho e pela paisagem social.

Os condomínios fechados marcam os novos estilos de vida das cidades, sendo os mesmos atrás de muros, vigias pessoais (identificação em guaritas) e formas tecnológicas de segurança 24 horas. Para Caldeira (2000), são esses requisitos que demarcam e isolam os mesmos do restante da cidade, com uma clara rejeição à vida pública nesta. Eles se configuram como espaços autônomos, independentes do entorno, podendo estar situados em qualquer lugar. Esse mesmo autor faz uma crítica a esses condomínios:

\begin{abstract}
Aqueles que escolhem habitar esses espaços valorizam viver entre pessoas seletas (...) e longe de interações indesejadas, movimento, heterogeneidade, perigo e imprevisibilidade das ruas. Os enclaves privados e fortificados cultivam um relacionamento de negação e ruptura com o resto da cidade e com o que pode ser chamado de um estilo moderno de espaço público aberto à livre circulação. Eles estão transformando a natureza do espaço público e a qualidade das interações públicas na cidade, que estão se tornando cada vez mais marcadas por suspeita e restrição (CALDEIRA, 2000, p. 259 apud SILVA et al., 2012, p. 4).
\end{abstract}

Afirma-se assim, a diferenciação social da cidade e as desigualdades socioespaciais que a especulação e mercados imobiliários estão produzindo.

No processo de compra da terra o proprietário irá utiliza-la de acordo com suas “necessidades". Então, donos de terrenos que possuem boa localização, que é valorizada de acordo com o que possuem próximos a si; por exemplo, comércio, centro da cidade; como afirma Corrêa (1989, p. 18) “agem pressionando o Estado visando à instalação da infraestrutura urbana”. Renda de monopólio: no fornecimento de determinada mercadoria: vantagem da localização: preço maior. Portanto essas áreas "são destinadas à população de status". Porém, por outro lado, para os proprietários de terras mal localizadas, em áreas periféricas, a alternativa economicamente viável é a construção de loteamentos populares, com o menor gasto possível em infraestrutura. Esses lotes são comercializados sem infraestrutura e a própria população moradora, passa a pressionar o Estado para que este promova a implantação da infraestrutura necessária (MAUTNER, 1999).

Esse crescimento urbano desordenado é socialmente injusto, pois um grande número dessa população fica restrita ao acesso a este bem, em mecanismo de mercado.

Restando a essa população áreas mal localizadas, que são desprivilegiadas quanto à acessibilidade aos principais centros de trabalho, oferta e qualidade de serviço e consumo. Moura e Ultramari (1996, p. 26) afirmam isso, "eleva consideravelmente o valor do solo urbano, e de maneira artificial. Cria uma demanda irreal que dificulta a satisfação da demanda verdadeira daqueles que, efetivamente, buscam comprar um imóvel”. 
Essa expansão urbana também afeta a organização do restante do espaço urbano, como também a distribuição espacial dos segmentos sociais na cidade. Com a incorporação dessas novas terras, amplia-se o perímetro urbano, alteram-se o valor das áreas recém incorporadas, devido ao serviço público realizado pelo Estado como: água encanada, geração de energia, linha de ônibus, escola pública, serviço de telefonia; mas também das áreas que já tinham localização periférica segundo o perímetro urbano anterior.

Porém, esses novos loteamentos terão seus preços mais elevados em relação aos moradores mais antigos, devido a empresas e famílias de renda elevada que estão dispostas a pagar mais para utilizar aquele espaço. Com essa elevação do preço dos imóveis, os antigos e pobres moradores podem se deslocar ou vender suas casas, beneficiando os novos residentes e não a quem realmente deveria beneficiar. Ou seja, a população que pode pagar a renda diferencial em serviços públicos, beneficia o mercado imobiliário.

Através da mobilidade urbana, seja pela expulsão de parte da população para a periferia, cria-se novos centros em função da demanda, de novas formas de uso e consumo do espaço como lazer e comércio, como consequência de valorização do lugar e dos novos investimentos ali produzidos. Essa valorização do espaço é desigual, causando em alguns momentos conflitos entre as populações locais:

A sociedade produz o espaço e, ao fazê-lo, revela uma profunda contradição, entre um processo de produção, que é socializado, e a produção do espaço, que é privada. Portanto, o espaço se produz, produzindo os conflitos latentes de uma sociedade fundada na desigualdade (uma sociedade hierarquizada em classes). (SPOSITO, 2012a, p. 68)

O processo de especulação imobiliária e segregação socioespacial, antes concentrada em grandes cidades começa a alterar a dinâmica das cidades pequenas e médias. As novas funções das cidades médias passam sobretudo na influência sobre as pequenas cidades desde ao setor de serviços, comércios, de saúde e educação, gerando uma rede de circulação de mercadorias e pessoas. Diante disso, Sposito (2001) apud Oliveira (2011, p. 21) fala:

[...] podemos caracterizar as "cidades médias", afirmando que a classificação delas, pelo enfoque funcional, sempre esteve associada à definição de seus papéis regionais e ao potencial de comunicação e articulação proporcionado por suas situações geográficas, tendo o consumo um papel mais importante que a produção na estruturação dos fluxos que definem o papel intermediário dessas cidades. (SPOSITO, 2001, p. 635).

As cidades médias, tornam-se, portanto, cidades de referência regional para o consumo de bens e serviços especializados, mesmo não possuindo posição de comando no sistema econômico do país. Juntamente a esse processo, ocorre uma descentralização econômica das metrópoles. 


\subsection{A política habitacional: Estado, mercado e setor privado}

O Estado aproveitando-se da escassez de moradias para as classes populares e médias, devido ao processo acelerado de urbanização/industrialização e consequentemente migração campo-cidade, utiliza-se de programas como Minha Casa Minha Vida (PMCMV) e Conjuntos Habitacionais (COHAB'S) para estimular à produção e aquisição de novos imóveis. Através desses programas, o mesmo ganha apoio das classes populares, se validando de interesse legal de organização da vida em sociedade e, essas mesmas medidas são utilizadas pelo Estado como forma de uma possível conquista da casa própria. De acordo com Pires et al. (2014, p. 9)

Nesse sentido, a habitação insere-se no conjunto de serviços provisionados pelo Estado para a garantia de mínimos sociais, apontados como forma de assegurar um padrão mínimo de vida para todos os cidadãos, mas que assegura também a ordem social burguesa e seus processos de acumulação.

Portanto, o Estado atua através de seus interesses individuais ou no lado privado ressaltando a demanda maior de capital. Podemos perceber também que o fato de "morar" se torna uma atividade econômica como mercadoria e, o Estado pode incentivar e atuar na atividade econômica como agente de desenvolvimento.

A extensão do capitalismo realizou a generalização do espaço como propriedade privada, criando a contradição entre o espaço produzido enquanto valor de uso e o espaço produzido enquanto valor de troca, com a separação radical entre espaço público e privado e aprofundamento da segregação, bem como a relação entre o Estado que domina o espaço, produzindo-o enquanto homogêneo, e o modo de apropriação que se quer diferencial. (SPOSITO, 2012a, p. 68).

Nesse contexto, que o espaço urbano vem sendo construído e expandido, privilegiando as classes altas e deixando de lado grande número de pessoas de classe desprivilegiada, ou seja, os pobres. Pois, é um pequeno número dessa população que tem acesso ao crédito da casa própria, e o problema habitacional não é resolvido.

Os moradores de baixa aquisição econômica, a fim de evitar pagamento de moradias de aluguel e firmarem sua existência na sociedade, buscam conquistar a casa própria. Porém, ao realizarem esse sonho ficam anos pagando pela mesma, o que se torna um aluguel da propriedade adquirida. Sobre isso Kowarick (2000) apud Moura (2011, p. 384):

\footnotetext{
A moradia é o mundo da sociabilidade privada, o que significa dizer ajuda mútua, brigas, rivalidades, preferências, tristezas, alegrias, aborrecimentos, planos, sonhos, realizações. É por outro lado, abrigo contra tempestades do sistema econômico. Mas é também os lócus onde se condensa a produção de discursos nos quais a casa própria é valorizada em relação a moradia de aluguel [...]. (KOWARICK, 2000, p. 84).
} 
Portanto para esse morador, a casa própria não é apenas considerada uma propriedade e sim que o mesmo conseguiu realizar o seu mais alto sonho e vencer na vida através de seus esforços.

Os novos loteamentos e condomínios são construídos após os empreendedores realizarem análises na cidade para escolher os pontos estratégicos para tais empreendimentos. Um condomínio de alto padrão é construído próximo ou em um bairro já conhecido por possuir famílias de renda alta e os loteamentos populares, já são construídos em bairros mais populares ou próximos a eles, possuindo moradores de baixa renda. O mesmo acontece com as COHAB's e Minha Casa Minha Vida. De acordo com Corrêa (1995) apud Moura (2011, p. 393):

\begin{abstract}
A complexidade da ação dos agentes sociais inclui práticas que levam a um constante processo de reorganização espacial que se faz via incorporação de novas áreas ao espaço urbano, densificação do uso do solo, deterioração de certas áreas, renovação urbana, relocação diferenciada da infra-estrutura e mudança, coercitiva ou não, do conteúdo social e econômico de determinadas áreas da cidade. (CORRÊA, 1995, p. 11)
\end{abstract}

Então, nota-se que essa reorganização social se deriva diretamente da ação e atuação dos agentes no espaço urbano, no qual o mesmo se transforma, se fragmenta e se articula.

Juntamente com a reorganização social está a expansão da cidade. Para tal expansão faz-se necessário novos loteamentos, portanto áreas não ocupadas se transformam em áreas para uso e ocupação. De acordo com isso Del Grossi (1991) apud Costa (2011, p, 361) fala:

Pela organização de seus bairros, pelas sucessivas modalidades de utilização de seu sítio, assim como por sua localização, a cidade é um reflexo de uma história, e a configuração do espaço, de uma evolução econômica e social, sendo, pois, mutável, por que é uma paisagem que reflete um espaço geográfico. (DEL GROSSI, 1991, p. 32)

O espaço urbano é fruto da modificação do rural, em que os processos de ocupação foram se transformando de acordo com as demandas do capital e da cidade. É comum encontrarmos áreas antes de pastagens ou agriculturas, voltadas hoje para os loteamentos, e esse cenário é recorrente em cidades em expansão, como é o caso das cidades médias.

\title{
4. OS LOTEAMENTOS E A VALORIZAÇÃO DO ESPAÇO URBANO EM ALFENAS
}

A cidade de Alfenas é considerada como média, e nos últimos anos ganhou importância para o setor imobiliário e da construção civil, devido ao crescimento populacional e sobretudo, aos investimentos em crédito para casa própria. Nesse sentido, os loteamentos horizontais criados em Alfenas entre 2010 e 2016, correspondem a 16 novos empreendimentos imobiliários. Como há uma diversidade de público para cada loteamento, nesse trabalho, foram agrupados de acordo com o perfil econômico que irão atender. Então, foram calculados e agrupados em Alto Padrão os 
loteamentos acima de R\$90.000,00 (06 empreendimentos); Médio Padrão os de R\$50.000,00 (09 empreendimentos) até R \$90.000,00 e Baixo Padrão os de R \$40.000,00 (01 empreendimentos). A figura 2, evidencia a quantidade e o grande salto de criação dos loteamentos.

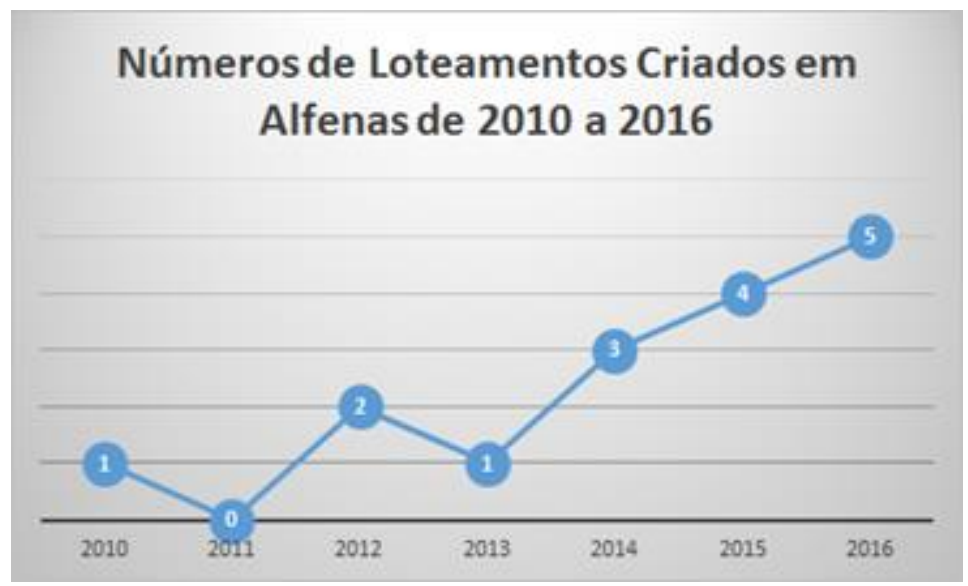

Figura 2 - Números de loteamentos horizontais criados em Alfenas - 2010 a 2016.

Elaborado: Autora, Janeiro de 2016.

Fica visível através da figura 2 que do ano de 2014 até 2016 houve a expansão significativa de loteamentos em Alfenas-MG, fato que pode ser ligado as políticas habitacionais em que favoreceram liberação de empréstimos para construção civil. Atrelado a esse fenômeno se tem a valorização de determinadas áreas, o déficit habitacional para algumas parcelas da população, a crescente especulação do mercado imobiliário e as competições entre os mesmos para o aumento de capital.

Contudo, esse crescimento de loteamentos horizontais não seguiram uma lógica do planejamento urbano, quanto a escolha dos lugares e infraestrutura existente, além de não levar em consideração o número de lotes desocupados existentes em bairros da cidade (Figura 3), ou seja, será que existe a necessidade da criação de todos loteamentos horizontais nos últimos 6 anos? E qual o público se destina esses novos empreendimentos imobiliários?

Conforme pode-se observar, os loteamentos horizontais criados após 2010 em Alfenas seguem duas direções praticamente, a direção oeste, sentido Unidade II da UNIFAL e Lago de Furnas, e direção leste nos arredores do bairro Jardim Aeroporto, com tendência a classe média-alta. E no meio dessa direção, há alguns que aproveitaram espaços vazios na área central da cidade, como diferencial no processo mercadológico do empreendimento. 


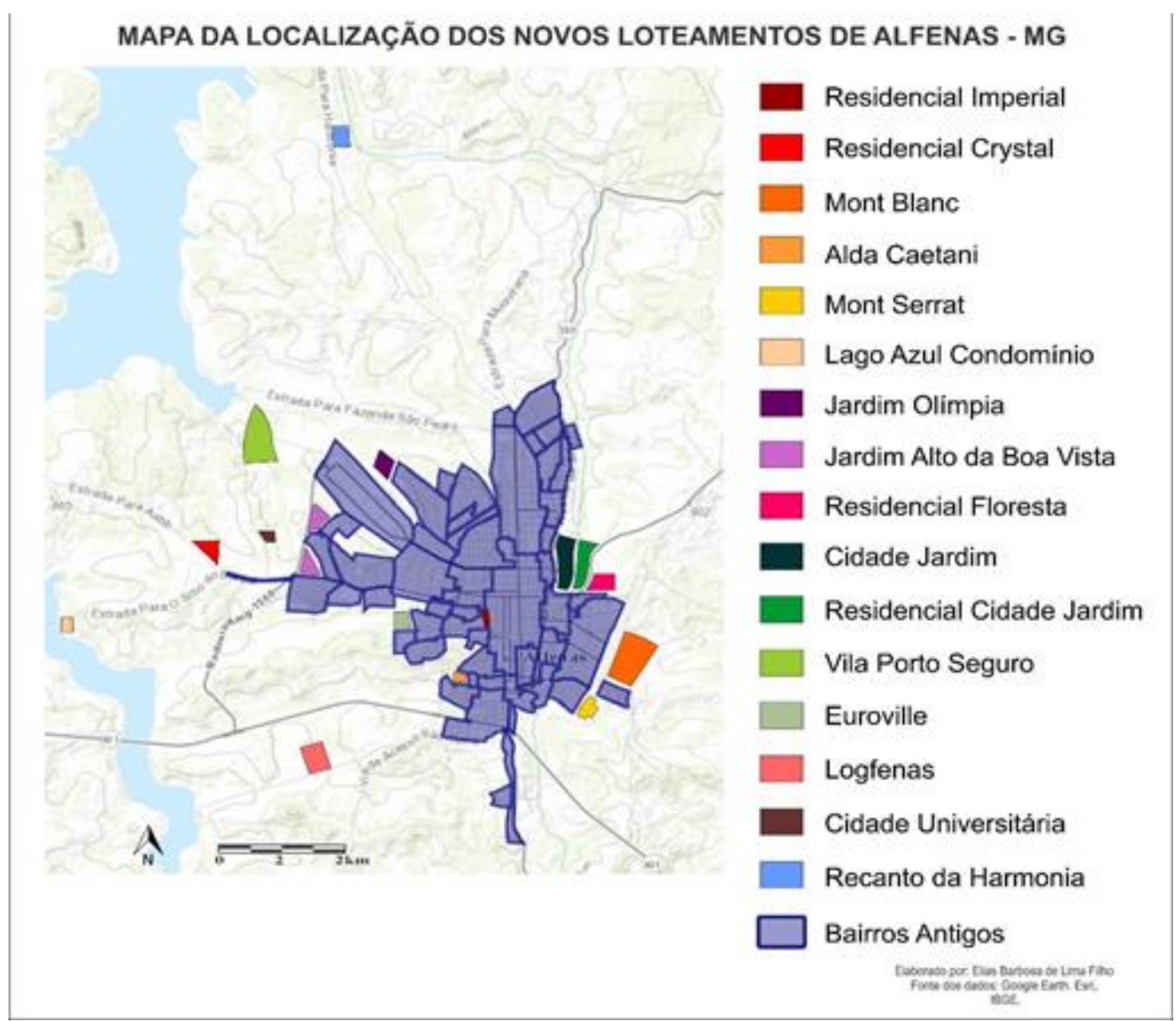

Figura 3 - Localização dos loteamentos horizontais criados entre 2010-2016 em Alfenas - MG. Elaborado por: Elias Barbosa. 04 de novembro de 2016.

Fonte: Google Earth, Esri e IBGE.

\subsection{Produção do espaço em Alfenas: demanda e especulação}

A partir dos dados obtidos e mostrados neste capítulo, somando a quantidade de lotes, Alfenas termina o ano de 2016 com 16 novos loteamentos em 6 anos, totalizando 3.373 lotes novos, ou seja, calculando uma casa com média de 4 pessoas, serão necessárias quase 15 mil pessoas para ocupar as novas residências/empreendimentos. Para o porte da cidade, fica visível a especulação imobiliária gerada nesse processo. Considerando a população estimada pelo IBGE em 2016 de 79 mil habitantes, seria necessário um incremento de quase $20 \%$ da população total para ocupar esses lotes.

Faltou por parte do poder público, estudos que apontassem a real necessidade dos empreendimentos imobiliários em Alfenas, procuramos o setor público da cidade, para pedir sua opinião sobre esses novos empreendimentos, mas não houve respostas. Conforme essa pesquisa mostrou, houve uma supervalorização do espaço urbano e os problemas de habitação-moradia, não 
serão sanados devido ao alto custo dos lotes e da falta de planejamento na organização dos novos bairros.

Outro fato observado através do trabalho de campo, foi a segregação explícita em alguns outdoors de loteamentos de médio e alto padrão como, por exemplo, Jardim Olímpia, Mont Blanc Residence e Residencial Chácaras Recanto da Harmonia. Nos outdoors dos mesmos possuem a representação de famílias compostos por pais brancos com crianças brancas, ao contrário do loteamento Residencial Crystal, no qual o outdoor possui família composto por pais negros com crianças negras. Este loteamento se encontra em zona periférica da cidade ao lado do bairro Santa Clara, onde a maioria dos moradores são negros. De acordo com Corrêa (2013, p. 44):

\footnotetext{
O mercado é visto como atuante, de modo implícito, no processo de segregação imposta e induzida. Mas esta é uma visão que considera o mercado como uma entidade supraorgânica, pairando acima da sociedade, e não como o resultado aparente de relações de poder. O mercado estabelece, como se argumenta, de modo equivocado, preços diferenciados da terra urbana e da habitação, levando à escolha segundo a capacidade que se tem de pagar pela moradia.
}

Portanto, não somente através do valor do lote há a segregação, como também através das propagandas vinculadas da sociedade para a sociedade, podendo assim levar a pessoa à escolha pela moradia no lugar determinado pela sua renda.

Outro fator que também podemos identificar nas propagandas é a desigualdade também explícita, pois os outdoors contendo famílias brancas e localização "boa" dizem que somente os brancos possuem riqueza, contradizendo o outdoor contendo a família negra com localização "ruim".

Uma desigualdade que se assenta na posse centralizada da riqueza social gerada por toda a sociedade nas mãos de uma classe social, que é também detentora do poder, o que permite estabelecer as condições de sua reprodução numa aliança entre os planos político e econômico contra o social. Essa realidade encontra seu fundamento, portanto, no desenvolvimento do capitalismo, no mundo moderno como formas de alienação [...]. (CARLOS, 2015, p. 43).

Portanto, faz-se necessário o cuidado ao se fazer e na escolha das propagandas que serão mostradas nos loteamentos e veiculadas ao público, para não ocorrer a exclusão de forma a se dizer onde se encontra o poder e a riqueza na realidade e no mundo moderno em que vivemos.

\section{CONSIDERAÇÕES FINAIS}

Mediante a análise dos textos e dos resultados encontrados nas pesquisas de campo, foi possível notar que na cidade de Alfenas-MG, está ocorrendo uma crescente especulação imobiliária, ou seja, em que a maioria está vinculado a uma antecipação e uma possível futura valorização de um determinado espaço. Por ser uma cidade média, com um grande fluxo de pessoas de cidades 
vizinhas, que vêm até a mesma à procura de bens de consumo, estudos, devido as duas universidades, emprego e tratamento diversos de saúde, e por possuir dois hospitais de referência, agora passa a ser um atrativo dos empreendedores, movimentando-a ainda mais, sobretudo com os fluxos de capitais e empregos por partes das loteadoras.

Nota-se que, por parte da Prefeitura Municipal de Alfenas, não ocorreu um planejamento correto para o lançamento dos novos loteamentos, tendo em vista o elevado número de empreendimentos e pelo porte da cidade, como dito anteriormente, não existe demanda para tudo isso, ao menos em curto-médio prazo. O lado capitalista das construtoras e imobiliárias estão acima de qualquer planejamento urbano. A cidade está se transformando em um negócio em que a reprodução do espaço urbano está voltada aos interesses particulares dos grandes empresários.

Os loteamentos localizados nas áreas centrais e nobres da cidade possuem uma valorização maior, mesmo antes dessa antecipação, ocorrendo uma segregação socioespacial do espaço urbano, uma supervalorização e especulação, pois as imobiliárias tiram o máximo proveito da localização para denegrir as outras localidades da cidade chamando a atenção dos consumidores e compradores/ investidores somente para si e centro da cidade.

Fazendo uma comparação, os loteamentos fechados e abertos que estão próximos entre si e a bairros populares, estão mostrando nitidamente a diferenciação de classes e a seletividade próximas, pois antes estavam distanciados devido à localização dos bairros na cidade. Outro exemplo é o loteamento popular localizado em área periférica da cidade, que antes se tratava de uma área rural, visto que através de seu valor de compra ajuda a confirmar que o lugar é desvalorizado, mas demonstra também que de médio a longo-prazo possa vir a ser um local de lucro devido proximidade com a universidade, potencializando o urbano como um negócio. Fica aqui uma pergunta, como fica a população necessitada de auxílio de moradia? Dado que os valores dos lotes não estão acessíveis a todos, uma vez que as condições que o país se encontra no atual governo, não favorece aos pobres para acesso a esse bem imobiliário.

No Brasil, como noticia-se em vários canais de informação, há um grande déficit de moradias e de direitos sociais. Esse déficit está ligado ao mal planejamento das prefeituras/governos estaduais e federais perante a população necessitada de seu auxílio, devido as baixas rendas familiares e ao grande desequilíbrio de classes. O que vemos no Brasil, pode ser ligado a cidade de Alfenas-MG, em que ocorre uma contradição entre a produção social do espaço e sua posse privada para a reprodução capitalista, provocando desde já uma desestrutura social e a reprodução da segregação dentro de seu próprio município. Juntamente com essa nova configuração do espaço urbano vão surgindo novos subcentros que são para atender as necessidades da nova demanda do lugar, ou seja, o capital sempre procurando uma forma de se acoplar ao novo lugar para sua própria reprodução. 
Esses novos loteamentos já configuram uma nova paisagem na cidade de Alfenas-MG, seja no meio urbano ou em alguns contrastes com o rural. Caberá então aos órgãos públicos uma nova análise futura desse processo, para a compreensão da dinâmica da formação da cidade entorno desses novos loteamentos, e também a necessidade de frear os novos empreendimentos imobiliários que vierem a aparecer, visto que fica visível diante os dados encontrados que a cidade não possui infraestrutura social e de gestão para as futuras famílias que ocuparão esses lotes.

\section{REFERÊNCIAS}

CARlos, A. F. A. A Tragédia Urbana. In: CARlOS, CARLOS, A. F. A.; VOLOCHKO, D.; ALVAREZ, I. P. (Orgs.). A cidade como negócio. São Paulo: Editora Contexto, 2015. p. 43-64.

CORRÊA, R. L. O Espaço urbano. São Paulo: Editora Ática S.A, 1989. 94p.

CORREAA, R. L. Segregação Residencial: classes sociais e espaço urbano. In: VASCONCELOS, P. A.; CORRÊA, R. L.; PINTAUDI, S. M. (Org.). A cidade contemporânea: segregação espacial. São Paulo: Contexto, 2013.

COSTA, R. A. Impactos e Riscos Ambientais Urbanos em Ituiutaba-MG. In: PORTUGUEZ, A. P.; MOURA, G. G.; COSTA, R. A. (Orgs.). Geografia do Brasil Central: enfoques teóricos e particularidades regionais. Uberlândia: Assis Editora, 2011.

HARVEY, D. A produção capitalista do espaço. São Paulo: Annablume, 2005. 252p.

IBGE CIDADES. Alfenas-MG. Disponível em: http://www.cidades.ibge.gov.br/xtras/perfil.php?lang=\&codmun=310160. Acesso em: 01 out. 2016.

INDICE MINEIRO DE RESPONSABILIDADE SOCIAL. Consultas/dados do IMRS. Disponível em: <http://imrs.fjp.mg.gov.br>. Acesso em: 23 nov. 2016.

MAUTNER, Y. A periferia como fronteira de expansão do capital. In: DEÁK, C.; SCHIFFER, S. R. (Orgs.). O processo de urbanização no Brasil. São Paulo: Edusp, 1999.

MOURA, G. G. Ituiutaba: Reflexos das condições sociais e da habitação na (re) estruturação urbana da cidade. In: PORTUGUEZ, A. P.; MOURA, G. G.; COSTA, R. A. (Orgs.). Geografia do Brasil Central: enfoques teóricos e particularidades regionais. Uberlândia: Assis Editora, 2011.

MOURA, R.; ULTRAMARI, C. O que é periferia urbana. 1. ed. São Paulo: Brasiliense, 1996. $61 \mathrm{p}$.

NASCIMENTO, E.; MATIAS, L. F. Expansão Urbana e Desigualdade Socioespacial: uma análise da cidade de Ponto Grossa (PR). RA'EGA, Curitiba, v. 23, p. 65-97, 2011.

OLIVEIRA, H. C. M. Cidades Médias: contribuições para o debate. In: PORTUGUEZ, A. P.; MOURA, G. G.; COSTA, R. A. (Orgs.). Geografia do Brasil Central: enfoques teóricos e particularidades regionais. Uberlândia: Assis Editora, 2011.

PÊSSOA, V. L. S. O Cerrado, antes dos "Inhambus, das Juritis, das Siriemas" agora do Agronegócio? As transformações no Pós 1970. In: FERREIRA, A.; RUA, J.; MARAFON, G.; 
SILVA, A. C. P. (Orgs.). Metropolização do espaço: gestão territorial e relações urbano-rurais. Rio de Janeiro: Consequência, 2013.

PIRES, V. R.; SILVA, L. A. M. Estado e Política Pública Habitacional no Brasil: alguns apontamentos. In: SIMPÓSIO DE DESENVOLVIMENTO TECNOLOGIA E SOCIEDADE, 4., Itajubá. Anais... Itajubá: UNIFEI, 2014. p. 4.

RUFINO, M. B. C. A Incorporação da Metrópole: algumas considerações sobre a produção imobiliária e a metropolização. FERREIRA, .; RUA, J.; MATTOS, R. C. (Orgs.). Metropolização do espaço: gestão territorial e relações urbano-rurais. Rio de Janeiro: Consequência, 2013.

SILVA, M. R.; CAMPOS, C. R.; FINIZOLA, C. F. G.; NOVAES, E. G.; ALVARES, L. C.; MOURA, M. L. V. Impactos Sociais e Urbanísticos dos Loteamentos Fechados no Setor Sul de Uberlândia - Um Estudo de Caso. Caminhos de Geografia, Uberlândia, v. 13, n. 43, p. 01-07, 2012.

SINGER, P. Economia Política da Urbanização. 1. ed. São Paulo: Editora brasiliense, 1987. $160 \mathrm{p}$.

SINGER, P. O uso do solo urbano na economia capitalista. In: MARICATO, E. A produção capitalista da casa (e da cidade) no brasil industrial. São Paulo: Alfa-Omega, 1978.

SPOSITO, M. E. B.; CARLOS, A. F. A.; SOUZA, M. L. A Produção do Espaço Urbano: agentes e processos, escalas e desafios. 1. ed. São Paulo: Contexto, 2012a. 240p.

SPOSITO, M. E. B. Capitalismo e Urbanização. 16. ed. São Paulo: Contexto, 2012b. 80p.

Trabalho recebido em 28/07/2019

Trabalho aceito em 30/07/2019 